\title{
Neutrophil Apoptosis During Viral Infections
}

\author{
Carole Elbim ${ }^{*}, 1$, Peter D. Katsikis ${ }^{2}$ and Jérôme Estaquier ${ }^{*}, 3$ \\ ${ }^{1}$ Centre de Recherche des Cordeliers, Université Pierre et Marie Curie-Paris 6, UMR S 872, Paris, F-75006 France ; \\ Université Paris Descartes, UMR S 872, Paris, F-75006 France ; INSERM, U872, Paris, F-75006, France \\ ${ }^{2}$ Department of Microbiology and Immunology, Drexel University College of Medicine, Philadelphia, PA 19129, USA \\ ${ }^{3}$ INSERM U955, Faculté Créteil Henri Mondor, Créteil, F-94000, France
}

\begin{abstract}
Apoptosis, or programmed cell death, is a highly conserved cellular suicide mechanism. Apoptosis is critical to the effective resolution of inflammation, particularly in regulating the lifespan of neutrophils. Neutrophils are key components of the first line of defense against microorganisms. Thus, subversion of this critical host defense mechanism by pathogens can contribute to susceptibility to severe and recurrent infections. In this review, we describe the molecular mechanisms involved in PMN death in relationship with viral infections.
\end{abstract}

\section{INTRODUCTION}

Polymorphonuclear neutrophils (PMN) contribute to the early innate response by rapidly migrating to inflamed tissues, where their activation triggers microbicidal mechanisms such as the release of proteolytic enzymes and antimicrobial peptides, and rapid production of reactive oxygen species (ROS), in the so-called oxidative burst.

PMN are terminally differentiated cells with a short life span in the circulation $(8-20 \mathrm{~h})$; aged PMN undergo spontaneous apoptosis (programmed cell death), in the absence of cytokines or other proinflammatory agents, prior to their removal by macrophages [1]. This phagocytic removal of intact, apoptotic neutrophils prevents them from releasing their cytotoxic content into the extracellular environment that would occur if the cells died by necrosis. Apoptosis is an intrinsic cellular process that can be regulated by external factors. In particular, PMN activation by circulating bacterial products, endogenous cytokines and other pro- inflammatory mediators can affect the rate of PMN apoptosis [2-4]. The prolongation of PMN life span is critical in their efficiency against pathogens [5]. Inappropriate PMN survival and persistence at sites of inflammation are thought to contribute to the pathology of chronic inflammatory diseases [6]. In contrast, shortened PMN survival due to apoptosis may contribute to susceptibility to severe and recurrent infections in some pathological situations $[7,8]$. Thus, the death program in PMN needs to be well controlled to provide appropriate balance between their immune functions and their safe clearance. Finally, PMN death contributes to PMN's pathogen killing capability. It is an essential step for the generation and the release of PMN extracellular traps (NETs), extracellular structures composed of chromatin, and granules proteins that bind and kill invading

*Address correspondence to these authors at the INSERM U955, Faculté Créteil Henri Mondor, 8 rue du Général Sarrail, 94010 Créteil, France; Tel: +331498136 72; E-mail: estaquier@yahoo.fr microorganisms. This mechanism allows PMN to fulfil their antimicrobial function even beyond their life span [9].

Pathogens, have evolved diverse mechanisms to evade the innate immune response and escape clearance by immune cells. Modulation of PMN apoptosis is recognized as a key mode of immune evasion, altering the timing of PMN death. This review point to some examples of viral infections associated with modulation of PMN apoptosis which may be involved at least in part in the pathophysiology of the disease.

\section{NEUTROPHIL APOPTOSIS}

PMN have a short life-span [10]. Apoptosis is one of the main types of cell death characterized so far [11]. PMN death display features of classical apoptosis, such as cell body shrinkage, cellular crenation, vacuolated cytoplasm, mitochondria depolarization, nuclear condensation, internucleosomal DNA fragmentation, and externalization of phosphatidylserine residues from the inner to the outer leaflet of the plasma membrane $[12,13]$. This externalisation facilitates the recognition of apoptotic neutrophils by macrophages [14-16]. Some of the features of classical apoptosis, including those observed in constitutive neutrophil death, are also shared by autophagic cell death [17].

Dying PMN show molecular alterations on their cell surface and is accompanied by the down-regulation of the immunoglobulin superfamily members (e.g. CD31, CD50, CD66acde, CD66b, CD63 and CD87) and cell surface receptors (e.g. CD15, CD16, CD32, CD35, CD88, CD120b) [18].

\section{MOLECULAR MECHANISMS OF NEUTROPHIL APOPTOSIS (FIG. 1)}

PMN apoptosis involves the activation of a family of cysteine proteases, called caspases, which cleave cellular substrates at an obligatory aspartic acid within a preferred sequence [19]. Caspase activation is a central event in apoptosis and results in the proteolytic degradation of multiple substrate proteins that contribute to the apoptotic 


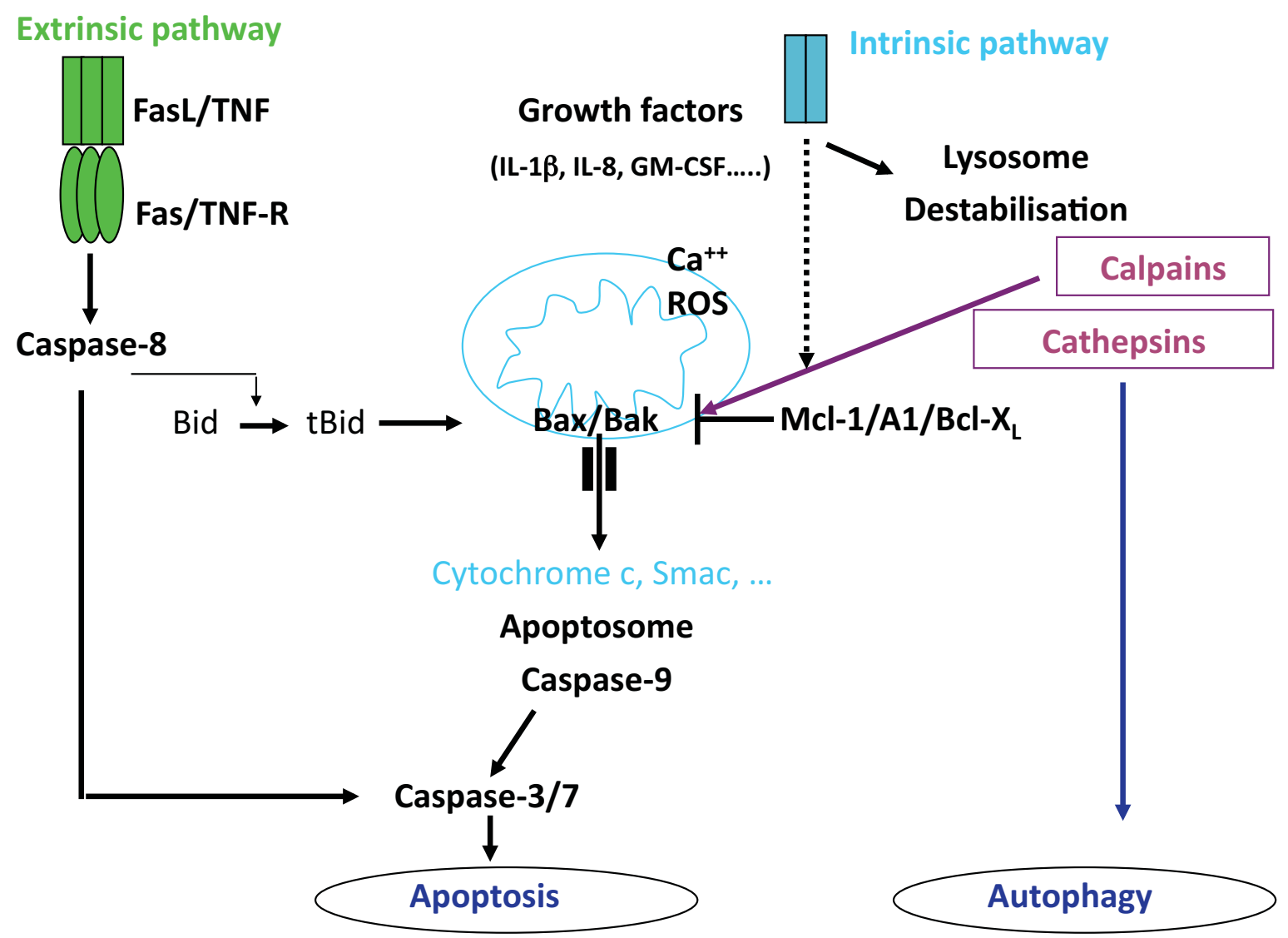

Fig. (1). Pathways leading to neutrophil death.

phenotype. Two major pathways that regulate apoptosis have been defined in a number of different cell types, including PMN. The first pathway depends on death receptors such as TNFRs and Fas (CD95) that can directly activate a caspase cascade via the activation of the caspase- 8 , an initiator caspase [20]. Bid, a pro-apoptotic members of the Bcl-2 family is cleaved [21]. Activated Bid is then translocated to mitochondria and can induce the release of cytochrome $c$ and other proapoptotic factors.

The second pathway termed intrinsic apoptosis pathway involves mitochondria and the Bcl-2 family members, and results in activation of caspase cascade via the activation of caspase-9 as an initiator caspase [22]. The release of mitochondrial cytochrome $c$ is under the control of the relative levels of pro- and anti-apoptotic members of the Bcl2 family [22].

PMN have been reported to express a variety of regulatory and effector caspases, including caspases-1, -3 and $-8[23,24]$. PMN contain barely detectable levels of cytochrome $c$; however, the trace of amount of cytochrome $c$ present in PMN is both necessary and sufficient for caspase activation [25].

It is now generally agreed that human PMN do not express the anti-apoptotic protein $\mathrm{Bcl}-2$ but they express mRNA for the anti-apoptotic proteins, Mcl-1, A1 and Bcl- $\mathrm{X}_{\mathrm{L}}$ $[4,26]$. Mcl-1 and A1 proteins are expressed in bloodstream neutrophils and their levels decrease prior to the onset of apoptosis $[4,26]$. Mcl-1 and A1 proteins have very short half lives (approximately 2-3 h) whereas the half lives of the pro- apoptotic proteins such as Bax, Bak and Bad, are relatively long. Hence, PMN apoptosis may be governed by the cellular levels of the relatively short-lived survival proteins, Mcl-1 and A1. In the absence of de novo synthesis of Mcl-1 and A1, the activity of the longer lived pro-apoptotic proteins prevails and tips the balance towards apoptosis. However, in the presence of survival signals (e.g. cytokines) the enhanced expression of the anti-apoptotic proteins, via pathways involving activated transcription, will ensure survival. It has been demonstrated that separate transcriptional signalling pathways leading to NF- $\mathrm{BB}$ and MAPKs activation regulate the expression of these proteins.

Calpains are a family of noncaspase cysteine proteases present in isolated PMN [27]. The ubiquitous calpain isoforms calpain-1 and calpain-2 are distinguished by their in vitro calcium requirements. During PMN spontaneous death, levels of calpastatin, a highly specific calpain inhibitor, decreases, leading to a drastic enhancement of the calpain-1 activity. Activated calpain-1 cleaves Bax into an active fragment [28]. Selective reduction of calpastatin by antisense oligodeoxynucleotides has been shown to accelerate spontaneous PMN apoptosis [29]. Further support for the importance of the calpastatin-calpain system was obtained by analysing PMN from patients with cystic fibrosis that exhibited delayed apoptosis. PMN display markedly increased calpastatin and decreased calpain-1 protein levels compared with PMN from healthy individuals [28]. More recently, it has been proposed that cathepsin D, a serine protease localized in the azurophilic granules, mediates caspase- 8 activity. Pharmacological or genetic inhibition of 
cathepsin D resulted in delayed caspase activation and reduced PMN apoptosis [30]. Furthermore, it has been reported that calpain mediates the cleavage of Atg5, an autophagy-related gene require for the formation of autophagosomes, swithching autophagy to apoptosis [31].

\section{MODULATION OF NEUTROPHIL APOPTOSIS}

The expression of constitutive PMN death programme can be delayed or accelerated by environmental factors.

\section{Antiapoptotic Factors}

PMN life-span increases significantly once they migrate out of the circulation and into the sites of inflammation, where they encounter various pro-inflammatory mediators. In particular, it has been reported that pro-inflammatory mediators including cytokines (IL-1 $\beta$, IL-2, TNF- $\alpha$, IL-15, IFN- $\gamma$, G-CSF, GM-CSF) can prolong PMN survival [2]. The reported effects of IL-6 on PMN apoptosis are controversial [32, 33]. IL-8, a chemokine, has also been shown to delay PMN apoptosis mediated by Fas and TNF- $\alpha$ receptors [34, 35].

Toll Like Receptors (TLR) agonists such as Malp2 (TLR2), LPS (TLR4), R-848 (TLR7/8), and CpG-DNA (TLR9) can also prolong PMN survival [4]. Treatment of PMN with such agents, that delay apoptosis, either increases or maintains Mcl-1 and A1 levels, providing a mechanism to explain cytokine-mediated increased survival via enhanced expression of anti-apoptotic proteins.

Similarly, a role of endothelial transmigration in the regulation of $\mathrm{PMN}$ apoptosis has been reported again indicating that adhesion molecules can generate intracellular signals that trigger enhanced survival of neutrophils as they migrate from the bloodstream into tissues [36, 37]. In this context, soluble ligand of $\alpha_{M} \beta 2$ integrin, including fibrinogen, delay PMN apoptosis through Akt activation [38].

\section{Proapototic Stimuli}

Fas signaling can mediate PMN apoptosis, and overrides the antiapoptotic effect of GM-CSF and TNF [39, 40]. An interaction between Fas and its counterpart, Fas ligand (FasL), was originally suggested to represent a mechanism to explain constitutive PMN apoptosis [41]. PMN express significant levels of Fas and whilst early reports indicated that they could also express FasL [41], this finding was not confirmed in later reports [42, 43]. PMN from CD95 deficient mice (lacking CD95) undergo apoptosis at the same rate as control mice, arguing against a role for the Fas system in constitutive apoptosis [44, 45]. Interestingly, it has been shown that membrane-bound form of Fas-L induce PMN infiltration in vivo which may be related to the release of IL$1 \beta$ from inflammatory cells [46]. Hence, the role of the Fas/FasL system in regulation of PMN apoptosis in inflammation and disease is still controversial.

\section{DYNAMICS OF NEUTROPHIL APOPTOSIS DURING VIRAL INFECTIONS}

Several lines of evidence suggest a key role of PMN, at least through defensin expression, in controlling viruses such as adenovirus, influenza virus and herpes simplex virus [4749]. In addition, human neutrophil $\alpha$-defensins 1-4 have been reported to inhibit HIV-1 replication in vitro [50-52], and activated PMN have been demonstrated to exert cytotoxic activity against HIV-infected cells [53]. PMN also attract and stimulate other immune cells through the release of proinflammatory chemokines and cytokines [54] and through direct interactions with immune cells such as dendritic cells [55], implying that PMN have the potential to orchestrate adaptive immune responses and play a key role during viral infections. Therefore, modulation of PMN survival during viral infections may have important consequences in disease evolution.

\section{Inhibition of PMN Apoptosis During Viral Infections (Table 1)}

\section{Respiratory Syncytial Virus(RSV) Inhibit PMN Apoptosis}

RSV, a ssRNA virus, is the major cause of lower respiratory tract disease (LRTD) in infants. In addition to virus-induced pathology, the immunological response to viral infection is thought to be responsible for disease pathogenesis, ultimately leading to respiratory distress. One of the characteristic phenomena of RSV LRTD is the presence of large numbers of neutrophils in the lower airways [56]. This is more profound than in any other viral respiratory condition in childhood in which mostly alveolar macrophages and lymphocytes prevail. It has been suggested that PMN may even contribute to the pathology observed in the airway. In this context, IL-9 production by PMN, which regulates mucus production by goblet cells, was found to be associated with severe RSV infection. In addition, it has been reported that RSV leads to an inhibition of the constitutive apoptotic program. This process was found to be dependent on both PI3K activity and NF- $\kappa \mathrm{B}$ activation. The antiapoptotic effect was abrogated by preincubation with the lysomotropic agent chloroquine, indicating the requirement for endolysosomal internalization. Furthermore, addition of ssRNA, a ligand for the intracellular TLR7/TLR8, also inhibited PMN apoptosis, suggesting that intracellular TLRs could be involved in induction of the antiapoptotic effect. IL6 , reported to inhibit neutrophil apoptosis, was present in supernatants from RSV-exposed PMN, suggesting that there is an autocrine or paracrine antiapoptotic role for IL-6. Finally, RSV treatment of PMN resulted in increased expression of the antiapoptotic $\mathrm{Mcl}-1$ protein [57]. Whether or not an increased neutrophil life span is to the benefit of the host is unclear. It also may be a non specific immune evasion technique evolved by viruses that may even be harmful to the host when occuring in neutrophils by increasing pathology to the airway.

\section{Human Cytomegalovirus (HCMV) Inhibit PMN Apoptosis}

HCMV is one of the eight viruses that belong to the herpes virus family. As with other herpes viruses, a primary HCMV infection is followed by life-long persistence of the virus in a latent state, and reactivation may occur repeatedly throughout life. Generally, HCMV infection is subclinically in immunocompetent individuals, but the virus can cause fatal disease in immunocompromised patients, for example after transplantation in AIDS patients and in the fetus. Patients undergoing active HCMV infection also have an increased risk of developing severe secondary clinical 
Table 1. Inhibition of PMN Apoptosis during Viral Infections

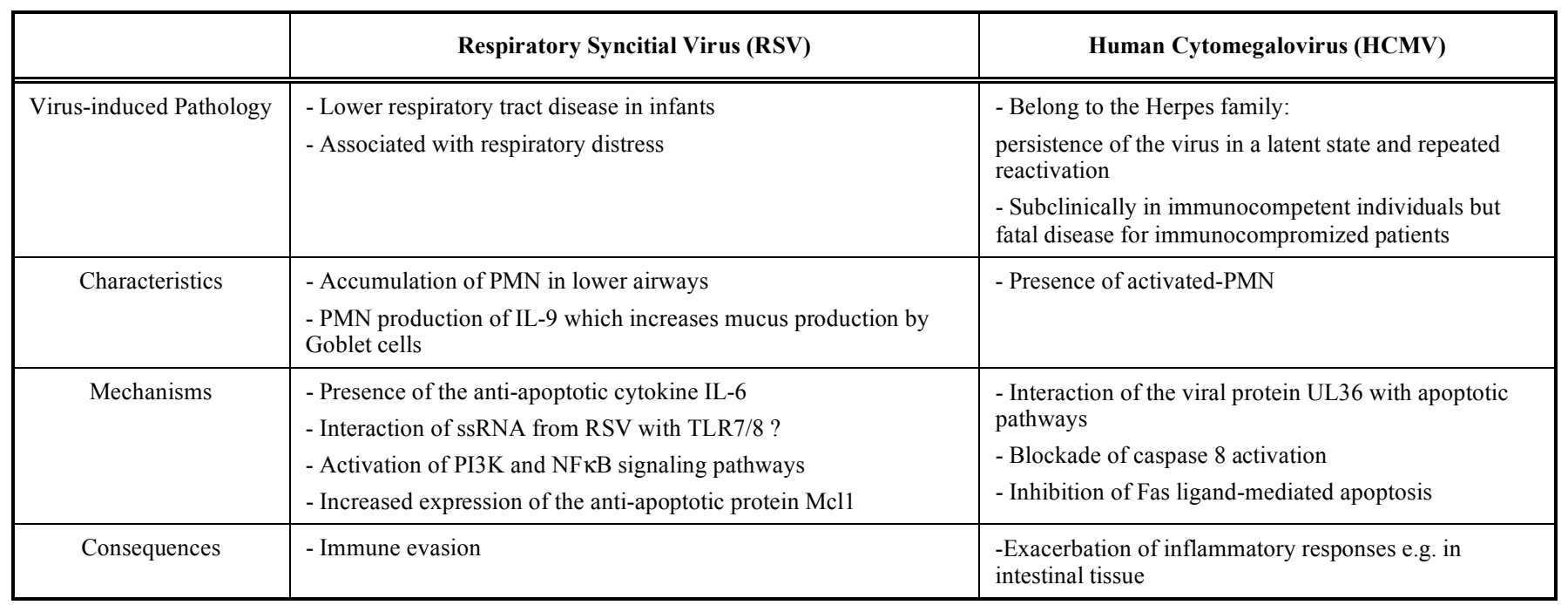

bacterial infections. This higher incidence of bacterial infections in HCMV patients may not be due directly to a dysfunction of PMN. Instead, HCMV-infected PMN become more activated, in terms of adhesion molecules expression and ROS production, than uninfected cells. Moreover, PMN apoptosis was significantly inhibited in HCMV-infected PMN [58]. This may be related to binding of the viral protein UL36 to caspase 8, blocking its activation and in this way inhibiting Fas-ligand-mediated apoptosis [59]. An additional anti-apoptotic effect may be mediated by the shedding of IL8 from the endothelial cells at the time of infection as suggested [60].

The fact that apoptosis is inhibited by HCMV may cause overreactive PMN creating inflammation. In this context, active HCMV infection in inflammatory cells, including PMN, has been reported in intestinal tissue sections from approximately $90 \%$ of patients with active inflammatory bowel disease (IBD) [61]. This may result in further aggravation of disease such as IBD and possibly also in other chronic inflammatory diseases.

\section{Exacerbation of PMN Apoptosis During Viral Infections (Table 2)}

\section{Exacerbation of PMN Apoptosis During HIV and SIV Infection}

The use of non-human primate models, particularly SIVinfected Asian Rhesus macaques (RMs), has allowed the detailed and sequential investigation of the events of SIV infection in terms of virus dynamics, immune response, and changes in the pool of $\mathrm{CD}^{+} \mathrm{T}$ cells [62]. Thus, SIVmac infection of RMs has proved an invaluable animal model for studies of AIDS pathogenesis, therapeutics, and vaccines. In particular, we and others have demonstrated that RMs of Chinese origin is a particularly relevant model to study human diseases [63-69].

Recently, we showed that PMN death increased early during the acute phase of SIV infection in RMs, and coincided with the peak of viral replication on day 14 postinoculation. The level of PMN death was significantly more severe in RMs that progress rapidly to AIDS and coincided with neutropenia. In contrast, no changes in the levels of
PMN death and PMN counts were observed in the nonpathogenic model of SIV infection of natural African Green Monkeys (AGMs) despite similar high viral replication. Consequently, the early increase in PMN death that we identified may account for the decline in PMN numbers that occurs during primary SIV infection and may, thus, have important implications for subsequent viral replication and disease progression. PMN death was a Bax and Bakindependent mitochondrial insult, which is prevented by inhibiting calpain activation but not caspase activation. Accelerated PMN death was not related to PMN infection, but we found that SIV particle binding to the cell surface is sufficient to prime PMN for death [70].

During the chronic phase, we also demonstrated that PMN from RM chronically infected with the virulent strain SIVmac251 display increased susceptibility to undergo apoptosis. PMN apoptosis was significantly increased in RMs progressing faster to AIDS as compared to non progressors RMs. Furthermore, the percentage of apoptotic cells correlated with PMN activation state reflected by increased $\mathrm{CD} 11 \mathrm{~b}$ expression and reactive oxygen species production. Interestingly, inflammatory cytokines IL-8 and IL-1 $\beta$ that prevent in vitro PMN death, were lower in RMs progressing towards AIDS. Thus, this decrease of inflammatory cytokines might lead to an abnormal tendency of PMN to die during the chronic phase. However, this is not reflected by an apparent decline of PMN counts. This result contrasts with the data observed during the acute phase demonstrating that PMN death is associated with neutropenia [71]. Increased PMN apoptosis has been also observed in HIV-infected patients having less than $200 \mathrm{CD}^{+}$ cells $/ \mathrm{mm}^{3}$ [72-78]; the introduction of HAART reducing spontaneous PMN apoptosis. This increased PMN apoptosis found in both HIV infection and pathogenic SIV models may also be due to increased translocation of gut bacterial products into the bloodstream that results from HIV/SIV associated enteropathy [79].

Increased emigration from the bone marrow of mature PMN could be an explanation for the absence of apparent depletion compensating cell death in chronically infected macaques. The consequences of PMN activation generating 
Table 2. Exacerbation of PMN Apoptosis During Viral Infections

\begin{tabular}{|c|l|l|}
\hline & \multicolumn{1}{|c|}{ HIV/SIV } & \multicolumn{1}{|c|}{ Influenza Virus A } \\
\hline \hline Virus-induced Pathology & - Immune deficiency & $\begin{array}{l}\text { - Bacterial superinfections which constitute the major } \\
\text { cause of morbidity and mortality }\end{array}$ \\
\hline Characteristics & $\begin{array}{l}\text { - Neutropenia during primary SIV infection } \\
\text { - No changes in the levels of PMN death and PMN counts in the } \\
\text { non-pathogenic model of SIV infection (AGM) }\end{array}$ & $\begin{array}{l}\text { - PMN infiltration of the airway } \\
\text { - Increased recruitment into the lung related to } \\
\text { chemokines }\end{array}$ \\
\hline Mechanisms & $\begin{array}{l}\text { - Increased expression of BOB/GPR5 } \\
\text { - Priming of PMN for death by particle binding to cell surface } \\
\text { - Calpain-dependent PMN death } \\
\text { - Bax and Bak-independent mitochondrial insult } \\
\text { - Lower expression of the anti-apoptotic cytokines IL-8 and IL-1B } \\
\text { during the chronic phase. }\end{array}$ & $\begin{array}{l}\text { - ROS-dependent PMN apoptosis } \\
\text { - Activation of PMN oxidative burst by the virus ? } \\
\text { - Increased expression of Fas antigen and Fas ligand }\end{array}$ \\
\hline Consequences & - Correlation with disease severity & \begin{tabular}{l} 
- Increased susceptibility to bacterial infections \\
\hline
\end{tabular}
\end{tabular}

general oxidative stress molecules might include an increased PMN susceptibility to apoptotic death during the chronic phase of infection [80]. In addition, these results support the idea that increased granulopoiesis in bone marrow leads to a compensatory release of mature PMN. Interestingly, PMN activation has been reported in the bone marrow of chronically SIV-infected macaques [81], contrasting with a defect in bone marrow lymphopoiesis [82, 83]. In fact, reciprocal dynamics of the bone marrow lymphocyte and neutrophil populations lead to cellular competition within a developmental niche. In particular, blocking bone marrow lymphopoiesis results in the specific and reciprocal expansion of the granulocytic compartment of bone marrow [84].

\section{Influenza A Viruses Increased PMN Apoptosis}

PMN have been reported to be involved in the initial host response to influenza A virus (IAV). Early after IAV infection, neutrophils infiltrate the airway probably due to release of chemokines that attract PMN [85]. Clearly, severe IAV infection is characterized by increased neutrophil influx into the lung or upper respiratory tract [86]. However, IAV also causes neutrophil dysfuction and accelerated neutrophil apoptosis [87, 88]. The latter effect is most pronounced when neutrophils are coincubated with IAV and bacteria, such as Escherichia Coli, Streptococcus pneumoniae [8892]. These effects appear to contribute to the predisposition of IAV-infected individuals to suffer bacterial superinfections. In particular, IAV infection appears to increase susceptibility to bacterial pneumonia, otitis and meningitis [93]. The reduced PMN recruitment in lungs post influenza virus infection clearly impairs protection against secondary bacterial infections. Although TLR desensitization may be a contributing factor for reduced recruitment [94], PMN apoptosis occurring during influenza virus infection may be a more likely explanation as these bacterial infections occur quickly after or during influenza virus infection. Such bacterial superinfections constitute a major cause of morbidity and mortality during IAV epidemics [93]. The ability of IAV to accelerate neutrophil apoptosis on exposure to bacteria may be related, at least in part, to the virus-induced respiratory burst response [89, 90]. In addition, IAV increased neutrophil expression of Fas antigen and Fas ligand into the cell supernatant [88].

\section{CONSEQUENCES OF PMN DEATH ON IMMUNE RESPONSE AND FUTURE PERSPECTIVES}

One consequence of such abnormal PMN apoptosis could be to facilitate the dissemination of viruses in vivo by modulating immune responses. Apoptotic cells are sources of biologically active oxidized phospholipids which serve as recognition signals on apoptotic cells, facilitating phagocytosis by macrophages [95]. Engulfment of apoptotic PMN has been shown to inhibit the production of proinflammatory mediators by macrophages, by secretion of anti-inflammatory cytokines such as TGF- $\beta$ [96, 97]. In this context, we recently demonstrated that TGF- $\beta$ is increased in the tissues of SIV-infected RMs [67]. Such antiinflammatory events can inhibit antigen presentation and promote microbial growth within macrophages [97], HIV replication [98] as well as the expansion of IL-17-producing cells [99, 100].

Altogether these data lead us to discuss the use of antiapoptotic PMN drugs in HIV-infected patients. It has been previously reported that G-CSF and GM-CSF exert potent stimulatory effect on PMN functions in $\mathrm{HIV}$-infected patients at the late stage of the disease [101, 102]. In addition, IL-15 significantly enhanced PMN functional activity and decreased the percentage of apoptotic PMN from untreated advanced HIV-infected patients [103]. Finally, Lichtner et al. have recently reported that HIV protease inhibitor (PI) therapy reverses in vitro $\mathrm{PMN}$ apoptosis of AIDS patients by direct calpain inhibition [104]. Further studies are necessary to evaluate the in vivo effect of such anti-apoptotic factors in non-human primates models. Indeed, it remains to provide the proof of concept that inhibiting PMN death early after infection is beneficial for patients preventing further disease evolution to Aids.

Overall, PMN apoptosis or survival during viral infections can have important consequences in promoting or impairing the ability of the host to clear infection but also contribute or reduce infection-associated pathology.

\section{ACKNOWLEDGEMENT}

Funding from the ANRS to JE supported this work. 


\section{REFERENCES}

[1] Savill J, Dransfield I, Gregory C, Haslett C. A blast from the past: clearance of apoptotic cells regulates immune responses. Nat Rev Immunol 2002; 2: 965-75.

[2] Colotta F, Re F, Polentarutti N, Sozzani S, Mantovani A. Modulation of granulocyte survival and programmed cell death by cytokines and bacterial products. Blood 1992; 80: 2012-20.

[3] Murray J, Barbara JA, Dunkley SA, et al. Regulation of neutrophil apoptosis by tumor necrosis factor-alpha: requirement for TNFR55 and TNFR75 for induction of apoptosis in vitro. Blood 1997; 90: 2772-83.

[4] François S, El Benna J, Dang PMC, Pedruzzi E, Gougerot-Pocidalo MA, Elbim C. Inhibition of neutrophil apoptosis by Toll-like receptor agonists in whole blood: involvement of the phosphoinositide 3-kinase/Akt and NF- $\mathrm{kB}$ signaling pathways leading to increased levels of Mcl-1, A1 and phosphorylated Bad. J Immunol 2005; 174: 3633-42.

[5] Haslett C, Savill JS, Whyte MK, Stern M, Dransfield I, Meagher IC. Granulocyte apoptosis and the control of inflammation. Philos Trans R Soc London Biol Sci 1994; 345: 327-33.

[6] Edwards SW, Hallett MB. Seeing the wood for the trees: the forgotten role of neutrophils in rheumatoid arthritis. Immunol Today 1997; $18: 320-4$.

[7] Aleman M, Schierloh P, de la Barrera SS, et al. Mycobacterium tuberculosis triggers apoptosis in peripheral neutrophils involving Toll-Like Receptor 2 and p38 mitogen protein kinase in tuberculosis patients. Infect Immun 2004; 72: 5150-8.

[8] Ramirez MJ, Titos E, Claria J, Navasa M, Fernandez J, Rodes J. Increased apoptosis dependent on caspase-3 activity in polymorphonuclear leukocytes from patients with cirrhosis and ascites. J Hepatol 2004; 41: 44-8.

[9] Fuchs TA, Abed U, Goosmann C, et al. Novel cell death program leads to neutrophil extracellular traps. J Cell Biol 2007; 176: 23141.

[10] Akgul C, Moulding DA, Edwards SW. Molecular controls of neutrophil apoptosis. FEBS Lett 2001; 487: 318-22.

[11] Zhivotovsky B. Apoptosis, necrosis and between. Cell Cycle 2004; 3: 64-6.

[12] Payne CM, Glasser L, Tischler ME, et al. Programmed cell death of the normal human neutrophil : An in vitro model of senescence. Microsc Res Tech 1994; 28: 327-44.

[13] Naito M, Nagashima K, Mashima T, Tsuro T. Phosphatidylserine externalization is a downstream event of interleukin-1 betaconverting enzyme family protease activation during apoptosis. Blood 1997; 89: 2060-6.

[14] Vermes I, Haanen C, Steffens-Nakken H, Reutelingsperger. A novel assay for apoptosis. Flow cytometric detection of phosphatidylserine expression on early apoptotic cells using fluorescein labelled Annexin V. J Immunol Methods 1995; 184: 39-51.

[15] Savill J, Fadok V, Henson P, Haslett C. Phagocyte recognition of cells undergoing apoptosis. Immunol Today 1993; 14: 131-6.

[16] Savill J, Haslett C. Granulocyte clearance by apoptosis in the resolution of inflammation. Semin Cell Biol 1995; 6: 385-93.

[17] Tsujimoto Y, Shimizu S. Another way to die: Autophagic programmed cell death. Cell Death Differ 2005; 12 (Suppl 2): 1528-34.

[18] Dransfield I, Buckle A, Savill JS, McDowell A, Haslett C, Hogg N. Neutrophil apoptosis is associated with a reduction in CD16 (Fc gamma RIII) expression. J Immunol 1994; 153: 1254-63.

[19] Daigle I, Simon HU. Critical role for caspases 3 and 8 in neutrophil but not eosinophil apoptosis. Int arch Allergy Immunol 2001; 126: 147-56.

[20] Ashkenazi A, Dixit VM. Death receptors: signalling and modulation. Science 1998; 281: 1305-8.

[21] Gross A, Yin XM, Wang K, et al. Caspase cleaved BID targets mitochondria and is required for cytochrome $c$ release, while BCL$\mathrm{XL}$ prevents this release but not tumour necrosis factor-R1/Fas death. J Biol Chem 1999; 274: 1156-63.

[22] Tsujimoto Y, Shimizu S. Bcl-2 family: life-or-death switch. FEBS Lett 2000; 466: 6-10.

[23] Yamashita K, Takahashi A, Kobayashi S, et al. Caspases mediate tumor necrosis factor- $\alpha$-induced neutrophil apoptosis and downregulation of reactive oxygen production. Blood 1999; 93: 674-85.
[24] Santos-Beneit AM, Mollinedo F. Expression of genes involved in initiation, regulation, and execution of apoptosis in human neutrophils and during neutrophil differentiation of HL-60 cells. J Leukoc Biol 2000; 67: 712-24.

[25] Murphy BM, O'Neill AJ, Adrain C, Watson RWG, Martin SJ. The apoptosome pathway to caspase activation in primary human neutrophils exhibits dramatically reduced requirements for cytochrome $c$. J Exp Med 2003; 197: 625-32.

[26] Moulding DA, Quayle JA, Hart CA, Edwards SW. Mcl-1 expression in human neutrophils: regulation by cytokines and correlation with cell survival. Blood 1998; 92: 2495-502.

[27] Knepper-Nicolai B, Ssavill J, Brown SB. Constitutive apoptosis in human neutrophils requires synergy between calpains and the proteasome downstream of caspases. J Biol Chem 1998; 273: 30530-6.

[28] Altznauer F, Conus S, Cavalli A, et al. Calpain-1 regulates Bax and subsequent Smac-dependent caspase-3 activation in neutrophil apoptosis. J Biol Chem 2004; 279: 5947-57.

[29] Squier MKT, Sehnert AJ, Sellins KS, Malkinson AM, Takano E, Cohen JJ. Calpain and calpastatin regulate neutrophil apoptosis. J Cell Physiol 1999; 178: 311-9.

[30] Conus S, Perozzo R, Reinheckel T, et al. Caspase-8 is activated by cathepsin D initiating neutrophil apoptosis during the resolution of inflammation. J Exp Med 2008; 205: 685-98.

[31] Yousefi S, Perozzo R, Schmid I, et al. Calpain-mediated cleavage of Atg5 swithches autophagy to apoptosis. Nat Cell Biol 2006; 8: 1124-32.

[32] Afford SC, Pongracz J, Stockley RA, Crocker J, Burnett D. The induction by human interleukin- 6 of apoptosis in the promonocytic cell line U937 and human neutrophils. J Biol Chem 1992; 627: 21612-6.

[33] Biffl WL, Moore EE, Moore FA, Barnett CCJ. Interleukin-6 suppression of neutrophil apoptosis is neutrophil concentration dependent. J Leukoc Biol 1995; 58: 582-4.

[34] Kettritz R, Gaido ML, Haller H, Luft FC, Jennette CJ, Falk RJ. Interleukin-8 delays spontaneous and tumor necrosis factor-alphamediated apoptosis of human neutrophils. Kidney Int 1998; 53: 8491.

[35] Leuenroth S, Lee C, Grutkoski P, Keeping H, Simms HH. Interleukin-8-induced suppression of polymorphonuclear leukocyte apoptosis is mediated by suppressing CD95 (Fas/Apo-1) Fas-1 interactions. Surgery 1998; 124: 409-41.

[36] Ginis I, Faller DV. Protection from apoptosis in human neutrophils is determined by the surface of adhesion. Am J Physiol 1997; 272: 295-309.

[37] Watson RW, Rostein OD, Nathens AB, Parodo J, Marshall JC. Granulocytic differentiation of HL-60 cells results in spontaneous apoptosis mediated by increased caspase expression. J Immunol 1997; 158: 945-53.

[38] Pluskota E, Soloviev DA, Szpak D, Weber C, Plow EF. Neutrophil apoptosis: selective regulation by different ligands of integrin $\alpha_{\mathrm{M}} \beta 2$. J Immunol 2008; 181: 3609-19.

[39] Daigle I, Yousefi S, Colonna M, Green DR, Simon HU. Death receptors bind SHP-1 and block cytokine-induced anti-apoptotic. Nat Med 2002; 8: 61-7.

[40] Ottonello L, Tortolina G, Amelotti M, Dallegri F. Soluble Fas ligand is chemotactic for human neutrophilic polymorphonuclear leukocytes. J Immunol 1999; 162: 3601-6.

[41] Liles WC, Kiener PA, Ledbetter JA, Aruffo A, Klebanoff SJ. Differential expression of Fas (CD95) and Fas ligand on normal human phagocytes: implications for the regulation of apoptosis in neutrophils. J Exp Med 1996; 184: 429-40.

[42] Brown SB, Savill J. Phagocytosis triggers macrophage release of Fas ligand and induces apoptosis of bystander leukocytes. J Immunol 1999; 162: 480-5.

[43] Renshaw SA, Timmons SJ, Eaton V, et al. Inflammatory neutrophils retain susceptibility to apoptosis mediated via the Fas death receptor. J Leukoc Biol 2000; 67: 662-68.

[44] Fecho K, Cohen PL. Fas ligand (gld)- and Fas (lpr)-deficient mice do not show alterations in the extravasation or apoptosis of inflammatory neutrophils. J Leukoc Biol 1998; 64: 373-83.

[45] Villunger A, O'Reilly LA, Holler N, Adams J, Strasser A. Fas ligand, Bcl-2, granulocyte colony-stimulating factor, and p38 mitogen-activated protein kinase: Regulators of distinct cell death and survival pathways in granulocytes. J Exp Med 2000; 192: 64757. 
[46] Shudo K, Kinoshita K, Imamura R, et al. The membrane-bound but not the soluble form of human Fas ligand is responsible for its inflammatory activity. Eur J Immunol 2001; 31: 2504-11.

[47] Bastian A, Schafer H. Human alpha-defensin 1 (HNP-1) inhibits adenoviral infection in vitro. Regul Pept 2001; 101: 157-61.

[48] Fujisawa H. Inhibitory role of neutrophils on influenza virus multiplication in the lungs of mice. Microbiol Immunol 2001; 45: 679-88.

[49] Yasin B, Wang W, Pang M, et al. Theta defensins protect cells from infection by herpes simplex virus by inhibiting viral adhesion and entry. J Virol 2004; 78: 5147-56.

[50] Zhang L, Yu W, He T, et al. Contribution of human alpha-defensin 1,2 , and 3 to the anti-HIV-1 activity of CD8 antiviral factor. Science 2002; 298: 995-1000.

[51] Zhang L, Lopez P, He T, Yu W, Ho DD. Retraction of an interpretation. Science 2004; 303: 467.

[52] Wu Z, Cicchi F, Gentles D, et al. Human neutrophil alpha-defensin 4 inhibits HIV-1 infection in vitro. FEBS Lett 2005; 579: 162-6.

[53] Baldwin GC, Fuller D, Roberts RL, Ho DD, Golde DW. Granulocyte- and granulocyte-macrophage colony-stimulating factors enhance neutrophil cytotoxicity toward HIV-infected cells. Blood 1989; 74: 1673-7.

[54] Scapini P, Lapinet-Vera JA, Gasperini S, Calzetti F, Bazzoni F, Cassatella MA. The neutrophil as a cellular source of chemokines. Immunol Rev 2000; 177: 195-203.

[55] Gisbergen J, Sanchez-Hernandez M, Geijtenbeek TBH, van Kooyk Y. Neutrophils mediate immune modulation of dendritic cells through glycosylation-dependent interactions between Mac-1 and DC-SIGN. J Exp Med 2005; 201: 1281-92.

[56] McNamara PS, Ritson P, Selby A, Hart CA, Smyth RL. Bronchoalveolar lavage cellularity in infants with severe respiratory syncitial virus bronchiolitis. Arch Dis Child 2003; 88: 922-6.

[57] Lindemans C, Coffer PJ, Schellens IMM, de Graff PMA, Kimpen JLL, Koenderman L. Respiratory syncitial virus inhibits granulocyte apoptosis through a phosphatidylinositol 3-kinase and NF-кB-dependent mechanism. J Immunol 2006; 176: 5529-37.

[58] Skarman PJ, Rahbar A, Xie X, Söderberg-Nauclér C. Induction of polymorphonuclear leukocyte response by human cytomegalovirus. Microbes Infect 2006; 8: 1592-601.

[59] Skaletskaya A, Bartle LM, Chittenden T, McCormick AL, Mocarski ES, Goldmacher VS. A cytomegalovirus-encoded inhibitor of apoptosis that suppresses caspase- 8 activation. Proc Natl Acad Sci USA 2001; 98: 7829.

[60] Saez-Lopez C, Ngambe-Tourere E, Rosenzwajg M, Petit JC, Nicolas JC, Gozlan J. Immediate-early antigen expression and modulation of apoptosis after in vitro infection of polymorphonuclear leukocytes by human cytomegalovirus. Microbes Infect 2005; 7: 1139-49.

[61] Rahbar A, Boström L, Lagerstedt U, Magnusson I, SöderbergNauclér C, Sundqvist V. Evidence of active cytomegalovirus infection and increased production of IL- 6 in tissue specimens obtained from patients with inflammatory bowel diseases. Inflamm Bowel Dis 2003; 9: 154-61.

[62] Hurtrel B, Petit F, Arnoult D, Muller-Trutwin M, Silvestri G, Estaquier J. Apoptosis in SIV infection. Cell Death Differ 2005; 12 Suppl 1: 979-90.

[63] Ling B, Veazey RS, Luckay A, et al. SIV(mac) pathogenesis in rhesus macaques of Chinese and Indian origin compared with primary HIV infections in human. AIDS 2002; 16: 1489-96.

[64] Monceaux V, Ho Tsong Fang R, Cumont MC, Hurtrel B, Estaquier J. Distinct cycling $\mathrm{CD}^{+}$and $\mathrm{CD}^{+} \mathrm{T}$ cell profiles during the asymptomatic phase of simian immunodeficiency virus SIVmac251 infection in rhesus macaques. J Virol 2003; 77: 10047-59.

[65] Reiman KA, Parker RA, Seaman MS, et al. Pathogenicity of simian-human immunodeficiency virus SHIV-89.6P and SIVmac is attenuated in cynomolgus macaques and associated with early $\mathrm{T}$ lymphocyte responses. J Virol 2005; 79: 8878-85.

[66] Viollet L, Monceaux M, Petit F, et al. Death of $\mathrm{CD}^{+} \mathrm{T}$ cells from lymph nodes during primary SIVmac 251 infection predicts the rate of AIDS progression. J Immunol 2006; 177: 6685-94.

[67] Cumont MC, Monceaux V, Viollet L, et al. TGF-beta in intestinal lymphoid organs contributes to the death of armed effector CD8 T cells and is associated with the absence of virus containment in rhesus macaques infected with the simian immunodeficiency virus. Cell Death Differ 2007; 14: 1747-58.
[68] Monceaux V, Viollet L, Petit F, et al. $\mathrm{CD}^{+} \mathrm{CCR}^{+} \mathrm{T}$-cell dynamics during simian immunodeficiency virus infection of Chinese Rhesus Macaques. J Virol 2007; 81: 13865-75.

[69] Cumont MC, Diop O, Vaslin B, et al. Early divergence inlymphoid tissue apoptosis between pathogenic and nonpathogenic simian immunodeficiency virus infections of nonhuman primates. J Virol 2008; 82: 1175-8.

[70] Elbim C, Monceaux V, Mueller YM, et al. Early divergence in neutrophil apoptosis between pathogenic and non- pathogenic SIV infections of non-human primates. J Immunol 2008; 181: 8613-23.

[71] Elbim C, Monceaux V, François S, Hurtrel B, Gougerot-Pocidalo MA, Estaquier J. Increased neutrophil apoptosis in chronically SIV-infected macaques. Retrovirology 2009; 29: 1-6.

[72] Pitrak DL, Tsai HC, Mullane KM, Sutton SH, Stevens P. Accelerated neutrophil apoptosis in the acquired immunodeficiency syndrome. J Clin Invest 1996; 98: 2714-9.

[73] Baldelli F, Preziosi R, Francisci D, Tascini C, Bistoni F, Nicoletti I. Programmed granulocyte neutrophil death in patients at different stages of HIV infection. AIDS 2000; 214: 1067-9.

[74] Mastroianni CM, Mengoni F, Lichtner M, et al. Ex Vivo and in vitro effect of human immunodeficiency virus protease inhibitors on neutrophil apoptosis. J Infect Dis 2000; 182: 1536-9.

[75] Mastroianni CM, d'Ettorre G, Forcina G, et al. Interleukin-15 enhances neutrophil functional activity in patients with human immunodeficiency virus infection. Blood 2000; 96: 1979-84.

[76] Salmen S, Teran G, Borges L, et al. Increased Fas-mediated apoptosis in polymorphonuclear cells from HIV-infected patients. Clin Exp Immunol 2004; 137: 166-72.

[77] Lichtner M, Mengoni F, Mastroianni CM, et al. HIV protease inhibitor therapy reverses neutrophil apoptosis in AIDS patients by direct calpain inhibition. Apoptosis 2006; 11: 781-7.

[78] Salmen SH, Soyano A, Hernández D, Berrueta L. Mechanisms of neutrophil death in human immunodeficiency virus-infected patients: role of reactive oxygen species, caspases and map kinase pathways. Clin Exp Immunol 2007; 150: 539-45.

[79] Brenchley JM, Price DA, Schacker TW, et al. Microbial translocation is a cause of systemic immune activation in chronic HIV infection. Nat Med 2006; 12: 1365-71.

[80] Von Gunten S, Yousefi S, Seitz M, et al. Siglec-9 transduces apoptotic and nonapoptotic death signals into neutrophils depending on the proinflammatory cytokine environment. Blood 2005; 106: 1423-31.

[81] Silvestri G, Sodora DL, Koup RA, et al. Nonpathogenic SIV infection of sooty mangabeys is characterized by limited bystander immunopathology despite chronic high-level viremia. Immunity 2003; 18: 441-52.

[82] Thiebot H, Louache F, Vaslin B, et al. Early and persistent bone marrow hematopoiesis defect in Simian/Human Immunodeficy Virus-infected macaques despite efficient reduction of viremia by highly active antiretroviral therapy during primary infection. J Virol 2001; 75: 11594-602.

[83] Thiebot H, Vaslin B, Derdouch S, et al. Impact of bone marrow hematopoiesis failure on T-cell generation during pathogenic simian immunodeficiency virus infection in macaques. Blood 2005; 105: 2403-9.

[84] Ueda Y, Kondo M, Kelsoe G. Inflammation and the reciprocal production of granulocytes and lymphocytes in bone marrow. J Exp Med 2005; 201: 1771-80.

[85] Arndt U, Wennemuth G, Barth P, et al. Release of macrophage migration factor and CXCL8/interleukin-8 from lung epithelial cells rendered necrotic by influenza A virus infection. J Virol 2002; 76: $9298-306$.

[86] Kobasa D, Takada A, Shinya K, et al. Enhanced virulence of influenza A viruses with the haemagglutinin of the 1918 pandemic virus. Nature 2004; 431: 703-7.

[87] Hartshorn KL, Liou LS, White MR, Kazhdan MM, Tauber JL. Neutrophil deactivation by influenza A virus: role of hemagglutinin binding to specific sialic acid-bearing cellular proteins. J Immunol 1995; 154: 3952-60.

[88] Colamussi M, White M, Crouch E, Harsthorn K. Influenza A virus accelerates neutrophil apoptosis and markedly potentiates apoptotic effects of bacteria. Blood 1999; 93: 2395-403.

[89] Engelich G, White M, Hartshorn K. Influenza A virus markedly potentiates neutrophil apoptosis induced by bacteria: role of respiratory burst. Blood 1999; 94: 211a. 
[90] Engelich G, White M, Hartshorn KL. Neutrophil survival is markedly reduced by incubation with influenza virus and Streptococcus pneumoniae: role of respiratory burst. J Leukoc Biol 2001; 69: 50-6.

[91] Engelich G, White M, Harsthorn KL. Role of respiratory burst in cooperative reduction in neutrophil survival by influenza A virus and Escherichia Coli. J Med Microbiol 2002; 5: 484-90.

[92] Lee RM, White MR, Hartshorn KL. Influenza A viruses upregulate neutrophil Toll-Like Receptor 2 expression and function. Scand J Immunol 2006; 63: 81-9.

[93] Hartshorn KL, Reid KB, White MR, et al. Neutrophil deactivation by influenza A viruses: mechanisms of protection after viral opsonization with collectins and hemagglutination-inhibiting antibodies. Blood 1996; 87: 3450-61.

[94] Didierlaurent A, Goulding J, Patel S, et al. Sustained desensitization to bacterial Toll-like receptor ligands after resolution of respiratory influenza infection. J Exp Med 2008; 205 : 323-9.

[95] Kadl A, Bochkov VN, Huber J, Leitinger N. Apoptotic cells as sources for biologically active oxidized phospholipids. Antioxid Redox Signal 2004; 6: 311-20.

[96] Huynh ML, Fadok VA, Henson PM. Phosphatidylserine-dependent ingestion of apoptotic cells promotes TGF- $\beta 1$ secretion and the resolution of inflammation. J Clin Invest 2002; 109: 41-50.

[97] Laskay T, van Zandbergen G, Solbach W. Neutrophil granulocytes Trojan horses for Leishmania major and other intracellular microbes? Trends Microbiol 2003; 11:210-4.
[98] Lima RG, Weyenberg JV, Saraiva EMB, Barral-Netto M, GalvãoCastro B, Bou-Habib DC. The replication of human immunodeficiency virus type 1 in macrophages is enhanced after phagocytosis of apoptotic cells. J Infect Dis 2002; 185: 1561-6.

[99] Stark MA, Huo Y, Burcin TL, Morris MA, Olson TS, Ley K. Phagocytosis of apoptotic neutrophils regulates granulopoiesis via IL-23 and IL-17. Immunity 2005; 88: 285-94.

[100] Torchinsky MB, Garaude J, Martin AP, Blander JM. Innate immune recognition of infected apoptotic cells direct $\mathrm{T}(\mathrm{H}) 17$ cell differentiation. Nature 2009; 458: 78-82.

[101] Roilides E, Mertins S, Eddy J, Walsh TJ, Pizzo PA, Rubin M. Impairment of neutrophil chemotactic and bactericidal function in children infected with human immunodeficiency virus type 1 and partial reverse after in vitro exposure to granulocyte-macrophage colony-stimulating factor. J Pediatr 1990; 117:531-40.

[102] Vecchiarelly A, Monari C, Baldelli F, et al. Beneficial effect of recombinant human granulocyte colony stimulating factor on fungicidal activity of polymorphonuclear leukocytes from patients with AIDS. J Infect Dis $1995 ; 171$ : 1448-54.

[103] Mastroianni CM, d'Ettorre G, Forcina G, et al. Interleukin-15 enhances neutrophil functional activity in patients with human immunodeficiency virus infection. Blood 2000; 96: 1979-84.

[104] Lichtner M, Mengoni F, Mastroianni CM, et al. HIV protease inhibitor therapy reverses neutrophil apoptosis in AIDS patients by direct calpain inhibition. Blood 2006; 11: 781-7.

(C) Elbim et al.; Licensee Bentham Open.

This is an open access article licensed under the terms of the Creative Commons Attribution Non-Commercial License (http: //creativecommons.org/licenses/by-nc/ 3.0/) which permits unrestricted, non-commercial use, distribution and reproduction in any medium, provided the work is properly cited. 